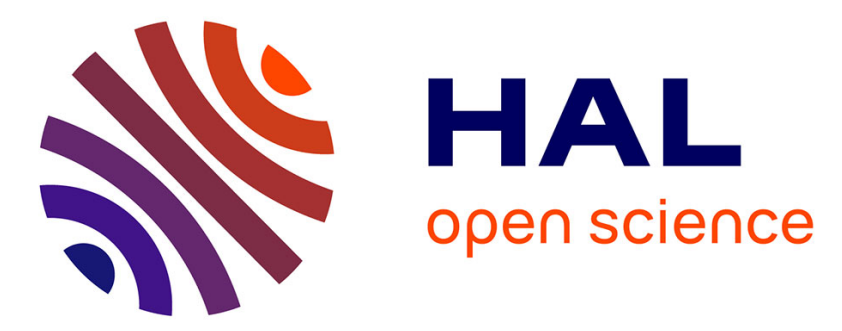

\title{
Differences in seed dormancy and germination in amphicarpic legumes: manifold bet-hedging in space and time
}

Ricardo Sánchez-Martín, José Maria Gómez, Pierre-Olivier Cheptou, Rafael Rubio de Casas

\section{To cite this version:}

Ricardo Sánchez-Martín, José Maria Gómez, Pierre-Olivier Cheptou, Rafael Rubio de Casas. Differences in seed dormancy and germination in amphicarpic legumes: manifold bet-hedging in space and time. Journal of Plant Ecology, 2021, 14 (4), pp.662-672. 10.1093/jpe/rtab019 . hal-03446730

\author{
HAL Id: hal-03446730 \\ https://hal.science/hal-03446730
}

Submitted on 24 Nov 2021

HAL is a multi-disciplinary open access archive for the deposit and dissemination of scientific research documents, whether they are published or not. The documents may come from teaching and research institutions in France or abroad, or from public or private research centers.
L'archive ouverte pluridisciplinaire HAL, est destinée au dépôt et à la diffusion de documents scientifiques de niveau recherche, publiés ou non, émanant des établissements d'enseignement et de recherche français ou étrangers, des laboratoires publics ou privés. 


\section{Original article}

\section{Running title: Bet-hedging in space and time}

3 Differences in seed dormancy and germination in amphicarpic 4 legumes: manifold bet-hedging in space and time

6 Sánchez Martín, R. ${ }^{1 *}$; Gómez, J. M²; Cheptou, P. O. ${ }^{3} \&$ Rubio de Casas, R. ${ }^{4 * *}$

$7{ }^{1}$ Departamento Ecología Vegetal. Centro de Investigaciones sobre Desertificación (CIDE8 CSIC-UV-GV). Carretera de Moncada-Náquera Km 4,5. 46113. Moncada (Valencia), Spain.

92 Estación Experimental de Zonas Áridas, EEZA-CSIC, Ctra. de Sacramento s/n, La Cañada 10 de San Urbano, 04120, Almería, Spain.

$11{ }^{3}$ CEFE UMR 5175, CNRS, Universite de Montpellier, Universite Paul-Valery, 7 Montpellier, 12 EPHE, 1919 route de Mende, 34293 Montpellier Cedex 05, France

$13{ }^{4}$ Departamento de Ecología, Universidad de Granada. Avda. de la Fuentenueva S/N, 18071. 14 Granada, Spain

16 *Corresponding authors: ricardo.sanchez@uv.es* 


\section{Abstract}

\section{Background and Aims}

3 Dispersal through space or time via dormancy is one of the primary processes whereby 4 organisms can influence the environment they experience. In plants, strong evolutionary 5 correlations are expected between the two kinds of dispersal because both are performed by 6 the seeds. In this paper, we investigate these evolutionary correlations using amphicarpic 7 plants, which produce simultaneously aerial seeds with high spatial dispersal propensity and 8 subterranean seeds that do not disperse.

\section{Methods}

10 We investigated the variation in dormancy and germination in aerial and subterranean seeds 11 of two amphicarpic legumes (Vicia amphicarpa and Lathyrus amphicarpos) and in two 12 closely related homocarpic taxa (V. sativa and $L$. cicera).

\section{Key results}

14 Our results showed complex interactions between spatial and temporal dispersal. Right after 15 dispersal, aerial seeds are more dormant than their subterranean counterparts, but this trend reverses with afterripening. Seeds of homocarpic plants germinate at higher percentages than any morph of their amphicarpic congeners and lose dormancy homogeneously with 18 afterripening.

\section{Conclusions}

20 The varied dormancy strategies of amphicarpic seeds are expected to increase variation in 21 emergence timing, providing multiple levels of diversifying bet-hedging. This strategy might 22 be adaptive under highly unpredictable conditions by enabling plants to rely on historically favorable sites in good seasons without preventing spatial and temporal migration.

Key Words: Dormancy/colonization trade-off, Environmental heterogeneity, Geocarpy, 26 Germination, Mediterranean environments, Physical dormancy, Lathyrus amphicarpos L., 


\section{Introduction}

2 Dispersal is one of the primary processes whereby organisms can influence the environment

3 they experience. An individual's fitness depends on its capacity to reach an appropriate habitat

4 for development and reproduction. Dispersal is usually regarded as the spatial displacement of

5 the progeny from the parental breeding site. However, dispersal also has a temporal dimension, as progeny emerging at different times experience different conditions and different population compositions from their parents. Temporal dispersal is often mediated by dormancy of the seeds or the eggs (Levin 1992). The distribution of progeny across heterogeneous environments will ultimately be determined by the interaction between spatial and temporal dispersal, i.e., by when and where offspring emerge.

In plants, dispersal results from the interaction of environmental factors (including dispersal vectors) and a propagule (the fruit or seed) whose phenotype is largely determined by the maternal plant. These interactions can result in a variety of outcomes, both in terms of distance to the maternal plant and the relative quality of the progeny patch. Dispersal of plants in time is determined to a large extent by seed dormancy (Donohue et al. 2010). Dormant seeds do not germinate under conditions generally favorable for germination (Finch-Savage and Leubner-Metzger, 2006). This state is often innate (i.e., seeds become "primary dormant" before detachment form the maternal plant) and lost with time in a process called "afterripening". However, seeds can also go through cycles oscillating between a germination ready state and one of "secondary" dormancy (Auge et al. 2015). For instance, physical dormancy or hardseededness (PY; prevention of germination by impermeable seed coats) is only attained under specific humidity and temperature conditions. In such instances, seeds might disperse in a non-dormant state and acquire PY if exposed to drought (Jaganathan 2016). Consequently, whether a seed is dormant will ultimately depend on its endogenous characteristics as well as on the environment that it encounters.

In some cases, plants can produce different types of seeds (Figure 1) that differ drastically in terms of their spatial dispersal propensity and/or dormancy level. This type of strategy termed seed heteromorphism, or heterospermy (Imbert 2002) is generally regarded as a bet-hedging mechanism, as the different morphs can disperse to different sites or germinate under different conditions increasing the likelihood that at least some of the progeny will be recruited at any given time (Venable 1985). Amphicarpy constitutes one of the most striking cases of heterospermy. Amphicarpic plants produce both aerial and subterranean (geocarpic) flowers 
1 and fruits (Darwin and Darwin 1880; Cheplick 1987). In amphicarpic species, a single plant 2 simultaneously produces two sets of dispersal structures that differ in practically all their characteristics. Seeds produced by the aerial flowers disperse without difficulty, while the subterranean seeds are inevitably limited in their dispersal capacity (Cheplick, 1994; Zhang et al., 2017). In addition, both types of seeds usually show differences in morphology as well as in dormancy (Baskin and Baskin 2014a). Generally, aerial parts produce a large number of seeds that are relatively small and dormant, while the subterranean fruits produce a smaller number of large, non-dormant seeds (Cheplick 1987; Kaul et al. 2000). Seed morph proportions are genetically controlled but also generally somewhat plastic and can vary depending on the maternal environment (Cheplick, 1994; Clavijo \& Jiménez, 1998; Sadeh et al., 2009).

Amphicarpy is assumed to derive from "homocarpy" (i.e., only aerial flowers and seeds) as a result of adaptation to highly unpredictable or frequently disturbed environments (Tardío 2000; Lev-Yadun et al. 2000; Gutterman 2002). The existence of the two different morphs might ensure reproduction and the possibility of leaving descendants even under recurring unfavorable conditions such as predation or fire (Darwin and Darwin 1880; Kaul et al. 2000). While dormant subterranean seeds can ensure recruitment within the maternal site, aerial seeds can colonize new patches (Ruiz de Clavijo 1995). However, in spite of this potential adaptive value, it is a rather unusual reproductive strategy. There are very few amphicarpic species, spread across phylogenetically distant families, such as Poaceae (e.g., Amphicarpum), Cyperaceae (Eleocharis), Brassicaeae (Cardamine) or Fabaceae (Amphicarpa, Macrotyloma, Lathyrus or Vicia), where it seems to be particularly frequent (Barker 2005). The rarity of the strategy and the fact that evolutionarily distant genera include amphicarpic species can be posited as evidence for adaptive convergence under particular environmental conditions. It is commonly assumed that amphicarpy can only be favored in highly unpredictable environments (Sadeh et al., 2009; Choo et al., 2015). Theoretical models have shown that this strategy provides an extreme case of diversifying bet-hedging, compromising short-term success to ensure high geometric mean fitness (Hidalgo et al., 2016). When conditions fluctuate drastically in both space and time, selection can favor simultaneously phenotypes that diversify risk through migration and those able to ensure the occupation of a previously favorable patch (Buoro and Carlson 2014; Rubio de Casas et al. 2015). In seeds, this can lead to the differentiation of two specialized morphs, a "High dispersal/High dormancy" seed (which migrates in space and time) and a "Low dispersal/Low dormancy" seed (which 
1 ensures occupation of the parental patch; Arshad et al., 2018). Amphicarpic plants might

2 conform to this model, as subterranean seeds are generally described as less dormant than 3 aerial ones (Cheplick 1994). The former would disperse neither in space nor in time, and

4 migration would be a function exclusively of the latter.

5 However, a trade-off between spatial and temporal dispersal is also commonly associated with heterospermy. In these cases, the morph that disperses more readily through space has limited dormancy (Imbert 2002; Baskin and Baskin 2014). For amphicarpic plants, this sort of evolutionary trade-off would have led to reduced dormancy in the aerial seeds (which would be specialized to disperse in space) relative to both their homocarpic ancestors and the subterranean morph. Simultaneously subterranean seeds should have developed relatively deep dormancy to provide dispersal through time. Therefore, comparing the behavior of homocarpic seeds (which have to ensure both spatial and temporal dispersal) to that of amphicarpic seeds might be useful to illustrate the potential existence of evolutionary tradeoffs between seed functions and whether bet-hedging causes specialization to disperse simultaneously in space and time.

In the present paper, we investigate evolutionary correlations and trade-offs in seed dispersal and dormancy by estimating differences in dormancy between seed morphs of two amphicarpic legumes, and between these and those of close homocarpic relatives with almost identical ecology and phenology. We aimed to establish if amphicarpy entails the specialization of seeds either as migrant (High dispersal/High dormancy) vs. persistent (Low dispersal/low dormancy) or as spatial (High dispersal/Low dormancy) vs. time (Low dispersal/High dormancy) capsules. To test these different scenarios, we investigated:

1. Whether different seed morphs (aerial vs. subterranean) of the Mediterranean amphicarpic legumes Lathyrus amphicarpos and Vicia amphicarpa differ in their germination and dormancy.

2. If seed dormancy is constant in time, i.e., if fresh and afterripened seeds exhibit similar levels of dormancy and whether these potential temporal differences vary between seed morphs.

3. If seeds from amphicarpic species, particularly aerial ones, differ in dormancy and germination from those of their closest homocarpic species, L. cicera and V. sativa, which share similar ecology and geographical distribution. 


\section{2. Materials and Methods}

\section{$3 \quad 2.1$ Plant species and dormancy classes}

4 We studied two amphicarpic species (Lathyrus amphicarpos and Vicia amphicarpa) and their closest non-amphicarpic relatives ( $L$. cicera and $V$. sativa). All four of these annual species belong to the tribe Fabeae of the Fabaceae, and are common, often co-occurring, in Mediterranean herbaceous communities in Southern Iberia. Besides their ecological requirements, the plants share many morphological synapomorphies within genera. The only trait differentiating $V$. amphicarpa and $V$. sativa is the production of subterranean reproductive structures in the former. In the case of the two Lathyrus, besides the subterranean flowers and fruits, morphological differences are limited to the abaxial shape of the fruit pods and the ramification of the tendrils (Gallego 2009). These ecological and morphological similarities are probably a consequence of the close evolutionary relationships (in fact, $V$. amphicarpa is often considered as a subspecies of V. sativa; Kenicer et al. 2005). The aerial fruits of these homocarpic and amphicarpic legumes are also similar and disperse their seeds ballistically, shooting them violently when the valves dehydrate in early summer (dehiscence; Garrison, Miller, \& Raspet, 2000), while subterranean fruits remain attached to the maternal plant.

Many legumes have seeds with hard and impermeable coats, which prevent water uptake (i.e., physical dormancy, PY). Under natural conditions, this type of dormancy is usually lost when seeds undergo temperature fluctuations that open the coats, which in the laboratory can be replaced by a mechanical scarification (Baskin et al. 2000; Baskin and Baskin 2000; Zalamea et al. 2015). Also, the seeds of certain Fabaceae can exhibit another class of dormancy, known as physiological dormancy (PD), which is caused by conditions within the embryo that prevent germination until inhibiting chemicals are broken down or are no longer produced by the seed. In nature, this deactivation is often caused by periods of storage in the seed bank under dry conditions (i.e., afterripening) followed by specific temperature combinations that ensure that the seeds germinate at the optimum moment for the development of the seedlings. For Mediterranean annuals that disperse their seeds at the onset of the dry season in early summer, the optimal germination season occurs in autumn, once temperatures have cooled down and water availability for seedling establishment can be reliably expected (i.e., winter annual life cycle). Therefore, PD is usually lost following a period of several weeks or months 
1 of dry afterripening and/or a short spell of cold temperatures $\left(\sim 4^{\circ} \mathrm{C}\right)$ under moist conditions

2 (Finch-Savage and Leubner-Metzger 2006; Baskin and Baskin 2014). In the laboratory, this is usually mimicked by dry storage at room temperature for several months (aprox. four) and short cold stratification (Varela and Arana 2011). However, when using dry storage, it is essential to keep in mind that in non-dormant seeds, post-dispersal drying might induce secondary dormancy, and thus dry afterripening might cause dormancy rather than alleviate it, specially if temperatures right after dispersal are high (Finch-Savage and Leubner-Metzger 2006). Furthermore, since PY is exogenous to the embryo and PD endogenous, the two dormancy classes might be present simultaneously in what is called combinational dormancy $(\mathrm{PY}+\mathrm{PD})$, which is relatively frequent in temperate legumes (Van Assche and Vandelook 2010).

\subsection{Experimental design}

Seeds were obtained from different populations across S. Spain, incorporating wide genetic variability (Figure S1). We collected three to twenty seeds from a total often to twelve individuals from 17 populations (three L. amphicarpos, four L. cicera and five of each of the Vicia species) and grew 10 random individuals from each of these populations under homogeneous conditions in a common greenhouse (IFAPA, Granada, Spain) allowing for open pollination within the greenhouse. After seed collection, some stock was saved so as to cultivate three descendants of each of the initial samples every year. Following the natural cycle of the plants, sowing took place at the beginning of October and mature seeds were collected in early June. This process was replicated several years and the seeds collected were used for the different germination experiments. Specifically, F1 seeds were used for experiment 1, F2 seeds for experiment 2 and F3 for experiment 3. F1 \& F2 plants were cultivated in the IFAPA greenhouses, and F3 in the 'Plateforme des Terrains d'Experience du LabExCeMEB' (Montpellier, France). In all germination experiments, seeds were pooled at the population level. The seeds of each species and seed morph were assigned to the same "type", i.e., amphicarpic plants had two seed types and homocarpic species had only one; as a result, all experiments included six seed types.

Experiment 1 was aimed at quantifying PY. In this experiment, we used seeds afterripened for eight months at room temperature to minimize potential PD effects on germination. Seeds underwent: an untreated control (treatment 0 hereafter) or mechanical scarification with nail pliers (treatment $\mathrm{S}$ hereafter). We used 10 replicates per treatment and seed type, each 
$1=60$ seeds/treatment $\times 6$ types $=360$ seeds). Once seeds were sowed, we sealed the dishes

2 with parafilm, analyzing germination percentage after, one, two, five, 11 and 14 days.

3 In Experiment 2, we used seeds that had undergone just four months of afterripening and were 4 therefore expected to retain some PD. This experiment was similar to Exp. 1 but we added 5 two new treatments: a cold dark stratification $\left(3^{\circ} \mathrm{C}\right.$ for 3 days, treatment $\left.\mathrm{C}\right)$ to check physiological dormancy and a combined treatment $(\mathrm{C}+\mathrm{S})$ to control for combinational dormancy (PY + PD).

To further clarify the effect of PD and estimate whether seeds at the time of dispersal lacked hardseededness and if secondary PY was a consequence of dry afterripening, a third experiment (Experiment 3) was carried out. For this experiment, seeds were harvested when plants had finished their cycle but were not yet fully dry (at least $75 \%$ of pods on each plant were yellow). They were then exposed to either control or cold stratification conditions (as described above).

In Experiments 1 \& 2, seeds were disinfected in $\mathrm{NaClO} 5 \%$ for 30 seconds prior to being sowed and cleaned with distilled water. In Experiment 3, we did not use any disinfection treatment to avoid any accidental opening of a water gap that may facilitate imbibition, which also caused a decrease in the number of final viable seeds (many seeds had to be discarded because of the presence of fungi, particularly in the case of the subterranean morphs). To ensure imbibition, $10 \mu \mathrm{L}$ of water were added to each seed after plating. Germination conditions were set at $21^{\circ} \mathrm{C}$ constant temperature and $12 \mathrm{~h}$ light cycles. Seeds were incubated under these conditions for 14 days in the first experiment and 11 days in the other two experiments. Germination, identified as a visible protrusion of the radicle, was checked every $48 \mathrm{~h}$ during incubation. At the end of each experiment, petri dishes were opened and seed viability assessed by firmness to touch, and non-viable seeds were discarded from all analyses.

\subsection{Data analysis}

Data was analyzed in R.3.3.1 (Team 2016) using generalized linear models with germination percentage as the response variable and seed type and treatment as fixed predictors. In every case, we selected the model with the best fit to the data based on AIC values. According to this criterion, linear models exhibited the best fit to the data of the two first experiments (Table S2. Supplementary materials) although our data did not conform to the assumptions of parametric models. We controlled for potential statistical artifacts by repeating all analyses 
1 using the model with the second lowest AIC value (Tweedie log; Table S2. Supplementary 2 materials). Since the results of both models were essentially identical, we kept the results of 3 the linear models. For the results of Experiment 3, the model selected was a negative binomial generalized model. In all models, we used the aerial amphicarpic morph of each genus as the reference level. That way, we can quickly test if these differ from either the subterranean seeds of the same species or the homocarpic seeds of close congeners.

\section{Results}

\subsection{Dormancy and germination of afterripened seeds}

Experiments $1 \& 2$ demonstrated the presence of PY in all seed types except those of Vicia sativa, which did not appear to have a significant degree of dormancy (Table 1; Fig. 2). Physical dormancy was particularly notable in amphicarpic species, especially in the subterranean seeds. Conversely, physiological dormancy and combinational dormancy did not influence germination of these species (Fig. 2). Cold stratification had only a significant effect on L. cicera and the subterranean seeds of L. amphicarpos, and in both cases its effect was much smaller than that of physical scarification, while neither $V$. amphicarpa morph nor the aerial seeds of $L$. amphicarpos responded to PD alleviation by cold stratification (Table 1; Fig. 2). In the absence of any dormancy breaking treatment, homocarpic species germinated to higher percentages than any amphicarpic seeds, while aerial seeds germinated to higher percentages than subterranean ones, although this last difference was only significant in $V$. amphicarpa (Fig. 2, Table 1).

\subsection{Dormancy and germination of fresh seeds}

The results of Experiment 3 demonstrated the presence of relatively deep primary dormancy in amphicarpic species. In this experiment, homocarpic species geminated better than amphicarpic ones. Aerial seeds of both amphicarpic species appeared to be particularly dormant. This dormancy was probably physiological to some degree because although cold stratification did not alleviate it, it was much diminished in afterripened seeds (Expp. 1 \& 2; Fig. 2). The seeds of L. cicera also seemed to have a relatively high level of dormancy, with \%germination $<40 \%$ and a complete absence of response to cold stratification. The subterranean seeds of L. amphicarpos had a similar degree of dormancy, but in this case, it 
1 was significantly reduced after cold stratification, which together with the results obtained

2 with AR seeds can be taken as indication of the presence of PD in these seeds. The seeds of $V$.

3 sativa also responded to cool stratification, although in this case, even control seeds had

$4 \%$ germination $>60 \%$ (Table 1 , Fig. 2).

5 Detailed model coefficients are available in supplementary material tablesS3-S8.

\section{Discussion}

Our results showed that amphicarpy entails variability in dispersal in time as well as in space. When compared to homocarpic seeds, amphicarpic seeds have greater dormancy overall. However, the two seed morphs produced by amphicarpic taxa differ significantly in their dormancy. Moreover, spatio-temporal dispersal patterns appear to be more diverse than expected, and no straightforward correlation between temporal and spatial dispersal could be established. Seed dormancy also seemed to be determined by the degree of after-ripening, but this effect differed among morphs, and as a result the behavior of each morph varied through time independently. The combination of multiple dormancy and dispersal levels within the seeds of individual maternal plants indicate that amphicarpy is a multifarious bet-hedging strategy that enables plants to spread risk spatially and temporally.

\subsection{Dormancy in aerial and subterranean seeds of amphicarpic plants}

Our results did not support the existence of a clear dormancy/colonization trade-off in amphicarpic plants or the differentiation of "High dispersal/High dormancy" and "Low dispersal/Low dormancy" strategies (Rees 1996; Arshad et al., 2018), but rather indicated the selection of more complex dormancy and dispersal strategies. The seeds of amphicarpic species exhibited in every case greater dormancy than the seeds of their closest congeners. The relative gain in physical dormancy was particularly prominent. However, physiological and combinational dormancy might also be ecologically relevant, especially in the case of subterranean seeds: initially they present a superficial physiological dormancy similar to aerial seeds of the other species (Exp. 3), but when dehydrated they acquire physical dormancy (Exp. $1 \& 2$ ). This suggests that in these seeds, afterripening modifies dormancy in a sophisticated fashion, increasing PY while simultaneously decreasing PD (Finch-Savage et al. 2007; Van Assche and Vandelook 2010; Baskin and Baskin 2014b).

Hardseededness appeared to be potentially deeper in subterranean seeds, which in both Lathyrus and Vicia had lower \%germination and responded more dramatically to scarification 
1 treatments than aerial seeds (Expp. $1 \& 2$ ). This difference among afterripened seeds of the

2 two morphs appeared to be more significant in $V$. amphicarpa than in L. amphicarpos, 3 although the trend was similar in both cases. However, these differences could be the result of secondary dormancy, likely induced by dehydration. Physical dormancy depends on the water content of the seed, the seed coat only becoming impermeable after partial dehydration (Van Assche et al. 2003; Jaganathan 2016). It would appear that the coats of subterranean seeds of amphicarpic species are initially water-permeable, as these seeds germinated better than fresh aerial seeds.

This shallow dormancy of subterranean seeds might allow them to germinate immediately after "dispersal", i.e., as soon as the seeds are mature, if the appropriate environmental conditions are met. These legumes have the typical Mediterranean annual life cycle, and mature their seeds at the end of the spring or early summer, concurrent with the onset of the dry summer period. Therefore, it is unlikely that subterranean seeds will encounter conditions adequate for germination, although given the stochasticity of the Mediterranean climate (Blondel and Aronson 2004), this might occur in exceptionally wet and cold years. In such instances, subterranean seeds might enable the re-occupation of the maternal spot before the regular germination season in the fall. However, they will most commonly dry during the summer, persist in the soil bank, and emerge scattered through time within the maternal patch (Zeide 1978; Tardío 2000). Thus, under realistic ecological conditions, hardseededness in underground seeds ensures temporal dispersal, but it can also provide temporal bet-hedging, adding to the differentiation of banking strategies associated to amphicarpy.

\subsection{Differences in germination and dormancy between amphicarpic and homocarpic relatives}

24 Our phylogenetically paired comparisons indicated that amphicarpy represents in every case an increase in seed dormancy. In both genera, amphicarpic seeds, either aerial or subterranean, displayed deeper dormancy that those of their homocarpic congeners. Dormancy was particularly shallow in the case of $V$. sativa, the seeds of which seemed to be almost entirely non-dormant. In homocarpic species, seeds appeared to be ready to germinate following four-months of dry afterripening. Under natural conditions, this would entail emergence in the fall of all the propagules dispersed earlier in the year and the absence of an inter-annual seedbank. 
1 Given the morphological similarities in the aerial fruits within genera, there is no reason to

2 expect drastic differences in the spatial dispersal between taxa. Lathyrus and Vicia disperse 3 their aerial seeds ballistically. However, amphicarpic species appear to have increased their 4 level of dormancy compared to their homocarpic relatives, which display a more evident colonizing behavior. At this point, it is unclear if that is because selection favors an overall increase in dormancy in all amphicarpic seeds or if the diversification of specialized dormancy types is somehow constrained in these species. Maybe the differentiation of a "dormant morph" limits the colonizing potential of the other morph, i.e., selection for increased dormancy might ultimately affect all of the seeds produced by a plant. Alternatively, it is possible that selection might have favored complex dormancy patterns in both seed types to ensure simultaneous seed banks in different locations. Such an outcome might be expected when environmental conditions are highly unpredictable in both space and time, which is the only scenario in which amphicarpy is expected to be adaptive (Hidalgo et al. 2016).

In summary, our results prove that the correlation between spatial and temporal seed dispersal can have in multiple different outcomes. There are no simple trade-offs between dispersal and dormancy and their joint evolution leads to the emergence of bet-hedging strategies that spread risk at multiple scales in both space and time.

\section{Acknowledgements}

This research was supported by the Spanish Ministries of Education and Professional Training (FPU grant FPU17/00629 awarded to RSM) and of Economy and Competitiveness (grant CGL2016-79950-R) including FEDER funds as well as by the Junta de Andalucía/FP7 Talentia program. We also thank the staff at the IFAPA Camino de Purchil and CEFE-CNRS greenhouses for their help with plant cultivation and Dr. D. Lawrence Venable for his helpful comments.

\section{Cited literature}

Arshad W, Sperber K, Steinbrecher T, et al. 2018. Dispersal biophysics and adaptive 29 significance of dimorphic diaspores in the annual Aethionema arabicum (Brassicaceae). New 30 Phytologist 221: 1434-1446.

31 Van Assche JA, Debucquoy KLA, Rommens WAF. 2003. Seasonal cycles in the 
germination capacity of buried seeds of some Leguminosae (Fabaceae). New Phytologist 158: 315-323.

Van Assche JA, Vandelook FEA. 2010. Combinational dormancy in winter annual

Auge GA, Blair LK, Burghardt LT, et al. 2015. Secondary dormancy dynamics depends on primary dormancy status in Arabidopsis thaliana. Seed Science Research 25: 230-246.

Barker N. 2005. A review and survey of amphicarpy, basicarpy and geocarpy in the African and Madagascan flora. Annals of the Missouri Botanic Garden 92: 445-462.

Baskin JM, Baskin CC. 2000. Evolutionary considerations of claims for physical dormancybreak by microbial action and abrasion by soil particles. Seed Science Research 10: 409-413.

Baskin CC, Baskin JM. 2014. Seeds : ecology, biogeography, and evolution of dormancy and germination. Elsevier Science.

Baskin CC, Baskin JM. 2014a. Variation in Seed Dormancy and Germination within and between Individuals and Populations of a Species. Seeds: 277-373.

Baskin CC, Baskin JM. 2014b. Germination Ecology of Seeds with Nondeep Physiological Dormancy. Seeds: 79-117.

Baskin JM, Baskin CC, Li X. 2000. Taxonomy, anatomy and evolution of physical dormancy in seeds. Plant Species Biology 15: 139-152.

Blondel J (Jacques), Aronson J. 2004. Biology and wildlife of the Mediterranean region. Oxford University Press.

Buoro M, Carlson SM. 2014. Life-history syndromes: Integrating dispersal through space and time (J Clobert, Ed.). Ecology Letters 17: 756-767.

Cheplick GP. 1987. The ecology of amphicarpic plants. Trends in ecology \& evolution 2: 97-101.

Cheplick G. 1994. Life History Evolution in Amphicarpic Plants. Plant Species Biology 9: 119-131.

Choo YH, Nam JM, Kim JH \& Kim JG. 2015. Advantages of amphicarpy of Persicaria thunbergii in the early life history. Aquatic Botany 121: 33-38.

Clavijo ER de \& Jiménez MJ. 1998. The Influence of Achene Type and Plant Density on Growth and Biomass Allocation in the Heterocarpic Annual Catanache lutea (Asteraceae). International Journal of Plant Sciences 159: 637-647.

Darwin C, Darwin F. 1880. The Power of Movement in Plants (Murray, Ed.). London.

Donohue K, Rubio de Casas R, Burghardt L, Kovach K, Willis CG. 2010. Germination, Postgermination Adaptation, and Species Ecological Ranges. Annual Review of Ecology, Evolution, and Systematics 41: 293-319.

Finch-Savage WE, Cadman CSC, Toorop PE, Lynn JR, Hilhorst HWM. 2007. Seed dormancy release in Arabidopsis Cvi by dry after-ripening, low temperature, nitrate and light shows common quantitative patterns of gene expression directed by environmentally specific 
sensing. The Plant Journal 51: 60-78.

2 Finch-Savage WE, Leubner-Metzger G. 2006. Seed dormancy and the control of

3 germination. New Phytologist 171: 501-523.

4 Gallego M. 2009. Lathyrus L. En: G. Blanca, B. Cabezudo, M. Cueto, C. Fernández López

5 \&amp; C. Morales Torres (eds.), Flora Vascular de Andalucía Oriental 2 In: Junta de

6 Andalucía, ed. Sevilla, 377-385.

Garrison WJ, Miller GL, Raspet R. 2000. Ballistic seed projection in two herbaceous species. American Journal of Botany 87: 1257-1264.

Gutterman Y. 2002. Survival Strategies of Annual Desert Plants.

Hidalgo J, Rubio Casas R, Muñoz MA. 2016. Environmental unpredictability and inbreeding depression select for mixed dispersal syndromes. BMC Evolutionary Biology 16: 71.

Imbert E. 2002. Ecological consequences and ontogeny of seed heteromorphism. Perspectives in Plant Ecology, Evolution and Systematics 5: 13-36.

Jaganathan GK. 2016. Influence of maternal environment in developing different levels of physical dormancy and its ecological significance. Plant Ecology 217: 71-79.

Kaul V, Kaul A., Sharma M. 2000. The subterranean flower. Current Science 78: 39-44.

Kenicer GJ, Kajita T, Pennington RT, Murata J. 2005. Systematics and biogeography of Lathyrus (Leguminosae) based on internal transcribed spacer and cpDNA sequence data. American Journal of Botany 92: 1199-1209.

Lev-Yadun S, Gopher A, Abbo S. 2000. Archaeology. The cradle of agriculture. Science (New York, N.Y.) 288: 1602-3.

Levin SA. 1992. The Problem of Pattern and Scale in Ecology: The Robert H. MacArthur Award Lecture. Ecology 73: 1943-1967.

Rees M. 1996. Evolutionary ecology of seed dormancy and seed size. Philosophical Transactions of the Royal Society of London. Series B: Biological Sciences 351: 1299-1308.

Rubio de Casas R, Donohue K, Venable DL, Cheptou P-O. 2015. Gene-flow through space and time: dispersal, dormancy and adaptation to changing environments. Evolutionary Ecology 29: 813-831.

Ruiz de Clavijo E. 1995. The Ecological Significance of Fruit Heteromorphism in the Amphicarpic Species Catananche lutea (Asteraceae). International Journal of Plant Sciences 156: $824-833$.

Sadeh A, Guterman H, Gersani M \& Ovadia O. 2009. Plastic bet-hedging in an amphicarpic annual: an integrated strategy under variable conditions. Evolutionary Ecology 35 23: $373-388$.

Schnee BK \& Waller DM. 1986. Reproductive Behavior of Amphicarpaea bracteata (Leguminosae), an Amphicarpic Annual. American Journal of Botany 73: 376.

Tardío F. 2000. Anficarpia: un curioso fenómeno del reino vegetal: plantas que emiten frutos 
1 tanto aéreos como subterráneos. Quercus 172: 40-43.

2 Team R. 2016. a Language and Environment for Statistical Computing. R Foundation for

3 Statistical Computing, Vienna, Austria (URL https://www. R-project.org).

4 Varela SA, Arana V. 2011. Latencia y germinación de semillas. Tratamientos

5 pregerminativos. Serie técnica. Sistemas forestales integrados. Sección Silvicultura en

6 Viveros. Cuadernillo 3.

7 Venable DL. 1985. The Evolutionary Ecology of Seed Heteromorphism. The American

$8 \quad$ Naturalist 126: 577-595.

9 Zalamea P-C, Sarmiento C, Arnold AE, Davis AS, Dalling JW. 2015. Do soil microbes 10 and abrasion by soil particles influence persistence and loss of physical dormancy in seeds of 11 tropical pioneers? Frontiers in Plant Science 5: 799.

12 Zeide B. 1978. Reproductive Behavior of Plants in Time. The American Naturalist 112: 63613639.

14 Zhang K, Baskin JM, Baskin CC, Yang X \& Huang Z. 2017. Effect of seed morph and 15 light level on growth and reproduction of the amphicarpic plant Amphicarpaea edgeworthii 16 (Fabaceae). Scientific Reports 7: 39886. 


\section{Tables}

3 Table1.

\begin{tabular}{|c|c|c|c|c|c|c|}
\hline \multicolumn{7}{|c|}{ A. Lathyrus } \\
\hline Morph & \multicolumn{2}{|c|}{ Experiment 1} & \multicolumn{2}{|c|}{ Experiment 2} & \multicolumn{2}{|c|}{ Experiment 3} \\
\hline $\begin{array}{l}\text { Amphicarpic (Aerial } \\
\text { - Control -) }\end{array}$ & $\mathrm{S}$ & $<0.0001^{*}$ & \begin{tabular}{|l}
$\mathrm{S}$ \\
$\mathrm{C}$ \\
$\mathrm{S}+\mathrm{C}^{1}$
\end{tabular} & $\begin{array}{l}<0.0001 * \\
0.478 \\
0.837 \\
\end{array}$ & $\mathrm{C}$ & 1 \\
\hline \multirow{2}{*}{$\begin{array}{l}\text { Amphicarpic } \\
\text { (Subterranean) }\end{array}$} & 0 & 0.151 & $\begin{array}{l}0 \\
S\end{array}$ & $\begin{array}{l}0.308 \\
<0.0001 *\end{array}$ & 0 & $0.0057 *$ \\
\hline & $\mathrm{S}$ & $0.001 *$ & $\begin{array}{l}\mathrm{C} \\
\mathrm{S}+\mathrm{C}^{1}\end{array}$ & $\begin{array}{l}0.207 \\
0.720\end{array}$ & $\mathrm{C}$ & 0.010 \\
\hline \multirow{2}{*}{ Homocarpic } & 0 & $0.0007 *$ & $\begin{array}{l}0 \\
S\end{array}$ & $\begin{array}{l}0.024^{*} \\
0.027 *\end{array}$ & 0 & $<0.0008^{*}$ \\
\hline & $S$ & $0.005^{*}$ & $\begin{array}{l}\mathrm{C} \\
\mathrm{S}+\mathrm{C}^{1}\end{array}$ & $\begin{array}{l}0.138 \\
1\end{array}$ & $\mathrm{C}$ & 1 \\
\hline \multicolumn{7}{|c|}{ B. Vicia } \\
\hline Morph & \multicolumn{2}{|c|}{ Experiment 1} & \multicolumn{2}{|c|}{ Experiment 2} & \multicolumn{2}{|c|}{ Experiment 3} \\
\hline $\begin{array}{l}\text { Amphicarpic (Aerial } \\
\text { - Control-) }\end{array}$ & $\mathrm{S}$ & $0.0015 *$ & $\begin{array}{l}\mathrm{S} \\
\mathrm{C} \\
\mathrm{S}+\mathrm{C}^{1}\end{array}$ & $\begin{array}{l}0.001^{*} \\
0.799 \\
0.996\end{array}$ & $\mathrm{C}$ & 0.999 \\
\hline \multirow{2}{*}{$\begin{array}{l}\text { Amphicarpic } \\
\text { (Subterranean) }\end{array}$} & 0 & $<0.0001 *$ & $\begin{array}{l}0 \\
S\end{array}$ & $\begin{array}{l}0.010 * \\
<0.0001 *\end{array}$ & 0 & $0.027 *$ \\
\hline & $S$ & $<0.0001^{*}$ & $\begin{array}{l}\mathrm{C} \\
\mathrm{S}+\mathrm{C}^{1}\end{array}$ & $\begin{array}{l}0.999 \\
1 \\
\end{array}$ & $\mathrm{C}$ & 0.994 \\
\hline \multirow{2}{*}{ Homocarpic } & 0 & 0.794 & $\begin{array}{l}0 \\
S\end{array}$ & $\begin{array}{l}0.0001^{*} \\
0.499\end{array}$ & 0 & $<0.0001 *$ \\
\hline & $S$ & $0.025^{*}$ & $\begin{array}{l}\mathrm{C} \\
\mathrm{S}+\mathrm{C}^{1}\end{array}$ & $\begin{array}{l}1 \\
0.499\end{array}$ & $\mathrm{C}$ & $0.040^{*}$ \\
\hline
\end{tabular}

Table 1. Statistical summary of the three germination experiments. In every test, \%germination of the aerial seeds of the amphicarpic species under the control (0) treatment was used as the reference level. For example, the values shown for Experiment 1 correspond to the difference between $\mathrm{S}$ and 0 aerial amphicarpic seeds, between subterranean amphicarpic seeds in both treatments (i.e., 0 and $S$ ) and aerial control seeds and between homocarpic seeds in both treatments and aerial control seeds. Treatment codes: 0 - control; $\mathrm{C}$ - cold dark stratification (3 days at $3^{\circ} \mathrm{C}-4^{\circ} \mathrm{C}$ ); $\mathrm{S}$ - physical scarification; $\mathrm{S}+\mathrm{C}$ : physical scarification followed by cold stratification. Only p-values are displayed, for other coefficients, please refer to Tables S3-S8. Values represent the significance of the comparison between each seed type and the reference for any given treatment. * Significant at $p<0.05$ 
